\title{
Desempenho de codornas de corte submetidas a diferentes níveis de proteína bruta e energia metabolizável
}

\author{
Performance of meat-type quails subjected the different levels of crude protein and \\ metabolizable energy
}

\author{
Bruno Bastos Teixeira ${ }^{\mathrm{I}}$ Aldrin Vieira Pires ${ }^{\mathrm{II}}$ Rogério de Carvalho Veloso ${ }^{\mathrm{II}}$ \\ Flaviana Miranda Gonçalves ${ }^{\text {II }}$ Eduardo Silva Cordeiro Drumond ${ }^{\mathrm{II}}$ Sandra Regina Freitas Pinheiro ${ }^{\mathrm{II}}$
}

\section{RESUMO}

\begin{abstract}
Objetivou-se avaliar o desempenho de codornas de corte, submetidas a diferentes níveis de proteína bruta (PB) e energia metabolizável (EM). Avaliaram-se 720 codornas distribuídas em delineamento em blocos ao acaso, em esquema fatorial (5x3), com cinco níveis de PB (18, 20, 22, 24 e 26\%) e três níveis de EM (2700, 2900 e 3100 $\left.\mathrm{ccal} \mathrm{kg}^{-1}\right)$. As análises foram realizadas utilizando-se o programa SAEG (2007). No período inicial, houve efeito quadrático da $P B$ e EM sobre o consumo de ração $(C R)$, efeito quadrático da $P B$ e linear da EM sobre o peso corporal (PC), efeito linear da interação EM e PB sobre o ganho de peso (GP) e conversão alimentar (CA). No crescimento, efeito quadrático da $E M$ e PB sobre o $C R$, efeito linear da EM e PB sobre o PC e CA, efeito quadrático da $P B$ e linear da EM sobre o GP. Na terminação, efeito linear da $E M$ e $P B$ sobre o $C R, P C$ e $C A$, efeito linear e quadrático da $E M$ e PB sobre GP. Na fase inicial, recomenda-se $26 \%$ de $P B e$

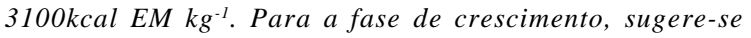

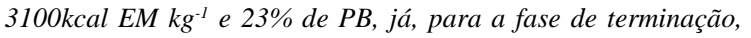

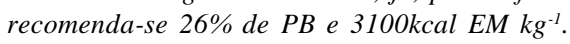

Palavras-chave: Coturnix coturnix, exigência, regressão, SAEG.

\section{ABSTRACT}

Aimed to evaluate the performance of meat-type quails, exposed to different levels of crude protein $(P B)$ and metabolizable energy (EM). We evaluated 720 quails distributed in randomized blocks design, in (5x3) factorial scheme, with five levels of $P B(18,20,22,24$ and 26\%) and three levels of EM (2700, 2900 and $\left.3100 \mathrm{kcal} \mathrm{kg}^{-1}\right)$. Analyses were performed using the program SAEG (2007). In the initial period, there was a quadratic effect of $P B$ and $E M$ on the feed intake (CR), quadratic effect of $P B$ and linear of EM about body weight
$(P C)$, linear effect of interaction of $P B$ and $E M$ about weight gain $(G P)$ and feed conversion (CA). Growth, quadratic effect of $E M$ and $P B$ about $C R$, linear effect of $P B$ and $E M$ on the $P C$ and $C A$, quadratic effect of $P B$ and linear effect of EM about GP. Upon termination, linear effect of $E M$ and $P B$ about $C R$, $P C$ and $C A$, linear and quadratic effect of EM and $P B$ about $G P$. In the initial phase, it is recommended $26 \%$ of $P B$ and $3100 \mathrm{kcal}$ EM $\mathrm{kg}^{-1}$. For the growth phase, it is suggested,

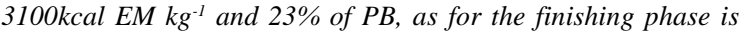

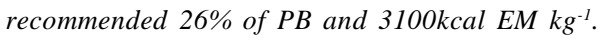

Key words: Coturnix coturnix, exigency, regression, SAEG.

\section{INTRODUÇÃO}

No Brasil, a coturnicultura é predominantemente voltada para produção de ovos, uma vez que a falta de material genético adequado, juntamente com a precariedade de dados sobre o desempenho e exigências nutricionais fazem com que muitos criadores explorem a produção de carne de forma pouco organizada e empírica (MÓRI et al., 2005).

Entre os fatores que incidem sobre o custo de produção das codornas, a alimentação pode representar mais de $70 \%$ do custo total. Portanto, existe a preocupação em oferecer rações com níveis nutricionais mais adequados às aves, que propiciem melhor desempenho e, consequentemente, maior retorno econômico. A proteína da ração, seguida pelo

'Departamento de Zootecnia, Universidade Federal de Viçosa (UFV), 36571-000, Viçosa, MG, Brasil. E-mail: brunobatzootecnia@yahoo.com.br. Autor para correspondência.

"Departamento de Zootecnia, Universidade Federal dos Vales do Jequitinhonha e Mucuri (UFVJM), Diamantina, MG, Brasil. 
componente energético, é o nutriente mais caro e seu balanceamento adequado deve melhorar a competitividade e o rendimento econômico das criações de codornas (SILVA et al., 2006).

São poucas as informações disponíveis na literatura sobre a nutrição de codornas de corte nas fases inicial, crescimento e terminação. Os programas de alimentação, normalmente utilizados no Brasil, seguem as recomendações do National Research Council (NRC, 1994), no qual são sugeridos diferentes planos nutricionais durante os períodos de desenvolvimento dessas aves. Entretanto, CORRÊA et al. (2007) relatam que essas recomendações não são apropriadas para as condições climáticas brasileiras, havendo necessidade do desenvolvimento de pesquisas com a finalidade de melhor adequar os programas nutricionais, ajustando-os com melhor precisão para as condições nacionais.

Segundo LISBOA et al. (1999), as adequações dos programas nutricionais permitem comparar diferentes linhagens de codornas presentes no mercado, a fim de verificar as mais produtivas e de qualidade superior, uma vez que as exigências entre linhagens são diferentes. Portanto, há a necessidade de se estabelecerem programas de melhoramento genético de codornas para produção de carne, bem como suas exigências nutricionais, além de desenvolver programas de alimentação visando a aperfeiçoar o desempenho e o rendimento de carcaça. Com este trabalho, objetivou-se avaliar o desempenho de codornas de corte, submetidas a diferentes níveis de proteína bruta e energia metabolizável.

\section{MATERIAL E MÉTODOS}

O estudo foi conduzido no galpão experimental do Programa de Melhoramento Genético de Codornas do Departamento de Zootecnia da Universidade Federal dos Vales dos Jequitinhonha e Mucuri, Campus JK, Diamantina, MG, localizada a 1380m de altitude.

Foi avaliado um grupo genético (Linha 01) de codorna europeia (Coturnix coturnix coturnix), no período de 23/10/2009 a 11/12/2009. Durante esse período, as aves foram criadas em bateria experimental, confeccionada em arame galvanizado, contendo comedouros, bebedouros e bandeja coletora de excretas. O sistema de aquecimento foi constituído por lâmpadas infravermelho de 250 watts. As codornas receberam água e ração à vontade durante todo o período experimental. Foram fornecidas 24 horas de luz (natural e artificial) durante as quatro primeiras semanas, após este período somente luz natural.

Foram avaliadas 720 codornas não sexadas, distribuídas em delineamento em blocos ao acaso, em esquema fatorial ( $5 \times 3)$, com cinco níveis de proteína bruta $(18,20,22,24$ e 26\%) e três níveis de energia metabolizável $\left(2700,2900 \mathrm{e} 3100 \mathrm{kcal} \mathrm{kg}^{-1}\right)$, em três blocos (repetições) com 16 codornas por unidade experimental. Os blocos foram constituídos pela posição das gaiolas no interior do galpão. As rações experimentais (Tabela 1) foram compostas a base de milho e farelo de soja, conforme informações de composições dos ingredientes apresentados por ROSTAGNO et al. (2000) e atendendo-se ás exigências nutricionais das codornas, de acordo com NRC (1994).

As variáveis de desempenho consumo de ração (CR), peso corporal (PC), ganho de peso (GP) e conversão alimentar (CA) foram analisadas em três períodos: inicial ( 1 aos 21 dias de idade), crescimento (1 aos 35 dias de idade) e terminação ( 1 aos 49 dias de idade), sendo pesadas aos 1, 7, 14, 21, 28, 35, 42 e 49 dias de idade. A ração fornecida e as sobras foram pesadas para o controle de consumo e conversão alimentar. As análises estatísticas de desempenho das codornas, em função dos níveis energéticos e proteicos das rações para estabelecimento das exigências nutricionais foram realizadas utilizando-se o procedimento Backward da regressão múltipla do programa SAEG (2007), para a escolha da equação que melhor se ajuste a cada variável analisada em cada período.

\section{RESULTADOS E DISCUSSÃO}

Os resultados da análise de regressão múltipla do consumo de ração (CR), peso corporal (PC), ganho de peso (GP) e conversão alimentar (CA) para o período inicial, estão apresentados na tabela 2. Houve efeito quadrático $(\mathrm{P}<0,01)$ da $\mathrm{PB}$ e EM sobre o $\mathrm{CR}$, onde $2549,80 \mathrm{kcal} \mathrm{EM} \mathrm{kg}^{-1}$ e $18,41 \%$ PB apresenta o menor CR $(341,47 \mathrm{~g})$, sugerindo que, elevando os níveis de PB e EM, poderá ocorrer um aumento no CR. Esses resultados diferem dos obtidos por FREITAS et al. (2006), que, em trabalho com codornas, verificaram que o CR foi influenciado apenas pelo nível de EM da ração, reduzindo o $\mathrm{CR}$ linearmente com o aumento do nível de EM. Tais resultados indicam que a PB junto com EM pode levar a um maior $\mathrm{CR}$.

Houve efeito quadrático $(\mathrm{P}<0,05)$ da $\mathrm{PB}$ e linear da EM sobre o PC, já que o fornecimento de $22,39 \%$ PB e $2700 \mathrm{kcal} \mathrm{EM} \mathrm{kg}^{-1}$ permitiu obter a máxima resposta para PC $(105,75 \mathrm{~g})$. Esses resultados contrariam 
Tabela 1 - Composições das rações experimentais utilizadas para codornas de corte do $1^{\circ}$ ao $49^{\circ}$ dia de idade, de acordo com o tratamento.

\begin{tabular}{|c|c|c|c|c|c|c|c|c|c|c|c|c|c|c|c|}
\hline \multirow{3}{*}{$\begin{array}{c}\text { Ingredientes } \\
(\%)\end{array}$} & \multicolumn{5}{|c|}{$2700 \mathrm{kcal} \mathrm{EM} \mathrm{kg}^{-1}$} & \multicolumn{5}{|c|}{$2900 \mathrm{kcal} \mathrm{EMkg}^{-1}$} & \multicolumn{5}{|c|}{$3100 \mathrm{kcal} \mathrm{EM} \mathrm{kg}^{-1}$} \\
\hline & \multicolumn{5}{|c|}{-------------Proteína bruta (\%)------------ } & \multicolumn{5}{|c|}{----'Proteína bruta (\%)----------- } & \multicolumn{5}{|c|}{ 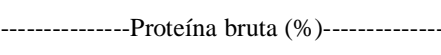 } \\
\hline & 18 & 20 & 22 & 24 & 26 & 18 & 20 & 22 & 24 & 26 & 18 & 20 & 22 & 24 & 26 \\
\hline Milho grão & 65,21 & 60,55 & 56,06 & 51,72 & 47,6 & 68,3 & 64,56 & 59,2 & 52,6 & 45,8 & 67,5 & 61,0 & 54,4 & 47,8 & 41,0 \\
\hline Farelo de soja & 29,55 & 34,35 & 38,99 & 43,47 & 47,9 & 26,6 & 31,52 & 36,9 & 42,6 & 48,3 & 26,4 & 32,1 & 37,8 & 43,5 & 49,2 \\
\hline L-Lysina & 0,50 & 0,32 & 0,15 & 0,00 & 0,00 & 0,53 & 0,35 & 0,16 & 0,00 & 0,00 & 0,53 & 0,34 & 0,15 & 0,00 & 0,00 \\
\hline $\begin{array}{l}\text { Inerte } \\
\text { (caulim) }\end{array}$ & 0,00 & 0,19 & 0,36 & 0,50 & 0,50 & 0,00 & 0,14 & 0,00 & 0,00 & 0,00 & 0,00 & 0,00 & 0,00 & 0,00 & 0,00 \\
\hline $\begin{array}{l}\text { DL- } \\
\text { Metionina }\end{array}$ & 0,23 & 0,20 & 0,16 & 0,13 & 0,10 & 0,21 & 0,18 & 0,16 & 0,13 & 0,10 & 0,21 & 0,18 & 0,16 & 0,13 & 0,11 \\
\hline $\begin{array}{l}\text { Fosf. } \\
\text { bicálcico }\end{array}$ & 1,71 & 1,65 & 1,58 & 1,52 & 0,92 & 1,60 & 1,01 & 0,98 & 0,95 & 0,92 & 1,05 & 1,02 & 0,99 & 0,96 & 0,93 \\
\hline Calcário & 1,92 & 1,87 & 1,82 & 1,78 & 1,95 & 1,83 & 1,35 & 1,09 & 1,06 & 1,04 & 1,12 & 1,10 & 1,08 & 1,05 & 1,03 \\
\hline Óleo soja & 0,00 & 0,00 & 0,00 & 0,00 & 0,00 & 0,00 & 0,00 & 0,61 & 1,75 & 2,88 & 2,21 & 3,35 & 4,48 & 5,62 & 6,76 \\
\hline $\begin{array}{l}\text { Premix Vit e } \\
\operatorname{Min}^{(1)}\end{array}$ & 0,50 & 0,50 & 0,50 & 0,50 & 0,50 & 0,50 & 0,50 & 0,50 & 0,50 & 0,50 & 0,50 & 0,50 & 0,50 & 0,50 & 0,50 \\
\hline Sal Comum & 0,35 & 0,35 & 0,35 & 0,35 & 0,35 & 0,35 & 0,35 & 0,35 & 0,35 & 0,35 & 0,35 & 0,35 & 0,35 & 0,35 & 0,35 \\
\hline Total & 100 & 100 & 100 & 100 & 100 & 100 & 100 & 100 & 100 & 100 & 100 & 100 & 100 & 100 & 100 \\
\hline $\begin{array}{l}\text { Proteína bruta } \\
(\%)\end{array}$ & 18,0 & 20,0 & 22,0 & 24,0 & 26,0 & 18,0 & 20,0 & 22,0 & 24,0 & 26,0 & 18,0 & 20,0 & 22,0 & 24,0 & 26,0 \\
\hline EM (kcal/kg) & 2700 & 2700 & 2700 & 2700 & 2700 & 2900 & 2900 & 2900 & 2900 & 2900 & 3100 & 3100 & 3100 & 3100 & 3100 \\
\hline Lisina $(\%)$ & 1,30 & 1,30 & 1,30 & 1,30 & 1,30 & 1,30 & 1,30 & 1,30 & 1,30 & 1,30 & 1,30 & 1,30 & 1,30 & 1,30 & 1,30 \\
\hline $\begin{array}{l}\text { Metionina } \\
(\%)\end{array}$ & 0,50 & 0,50 & 0,50 & 0,50 & 0,50 & 0,50 & 0,50 & 0,50 & 0,50 & 0,50 & 0,50 & 0,50 & 0,50 & 0,50 & 0,50 \\
\hline $\begin{array}{l}\text { Met. + Cist. } \\
(\%)\end{array}$ & 0,75 & 0,75 & 0,75 & 0,75 & 0,75 & 0,75 & 0,75 & 0,75 & 0,75 & 0,75 & 0,75 & 0,75 & 0,75 & 0,75 & 0,75 \\
\hline Cálcio (\%) & 0,80 & 0,80 & 0,80 & 0,80 & 0,80 & 0,80 & 0,80 & 0,80 & 0,80 & 0,80 & 0,80 & 0,80 & 0,80 & 0,80 & 0,80 \\
\hline $\begin{array}{l}\text { Fósf. } \\
\text { disponível } \\
(\%)\end{array}$ & 0,30 & 0,30 & 0,30 & 0,30 & 0,30 & 0,30 & 0,30 & 0,30 & 0,30 & 0,30 & 0,30 & 0,30 & 0,30 & 0,30 & 0,30 \\
\hline
\end{tabular}

${ }^{1}$ Premix vitamínico e mineral por kg de ração, vit. A 3.750.000UI; vit. $\mathrm{D}_{3}, 750.000 \mathrm{UI}$; vit. E $7500 \mathrm{mg}$; vit $\mathrm{K}_{3}, 1.000 \mathrm{mg}$; vit. $\mathrm{B}_{1}, 750 \mathrm{mg}$; vit. $\mathrm{B}_{2}$, $1.500 \mathrm{mg}$; vit. $\mathrm{B}_{6}, 1500 \mathrm{mg}$; vit. $\mathrm{B}_{12}, 7.500 \mathrm{mcg}$; vit. C $12.500 \mathrm{mg}$, biotina $30 \mathrm{mg}$, niacina $10.000 \mathrm{mg}$, ácido fólico $375 \mathrm{mg}$; ácido pantotênico $3.750 \mathrm{mg}$; colina $10.000 \mathrm{mg}$; metionina $400.000 \mathrm{mg}$; selênio $45 \mathrm{mg}$; iodo $175 \mathrm{mg}$; ferro $12.525 \mathrm{mg}$; cobre $2.500 \mathrm{mg}$; manganês $19.500 \mathrm{mg}$; zinco $13.750 \mathrm{mg}$; promotor de crescimento $15.000 \mathrm{mg}$; coccidiostático $10.000 \mathrm{mg}$; antioxidante (B.H.T) $500 \mathrm{mg}$;

os obtidos por CORRÊA et al. (2008), que verificaram que o $\mathrm{PC}$ foi influenciado significativamente $(\mathrm{P}<0,01)$ apenas pelo nível de $\mathrm{PB}$ da ração, pois 30,64\% de PB proporcionou um ponto de máximo para o $\mathrm{PC}(149,86 \mathrm{~g})$. Esses resultados indicam que uma variação no nível de EM, pode influenciar no PC das codornas. 
Tabela 2 - Regressão múltipla do consumo de ração (CR g ave ${ }^{-1}$ ), peso corporal ( $\mathrm{PC} \mathrm{g} \mathrm{ave}{ }^{-1}$ ), ganho de peso $\left(\mathrm{GP} g\right.$ ave $\left.\mathrm{g}^{-1}\right)$ e conversão alimentar $\left(\mathrm{CA} \mathrm{g} \mathrm{g}^{-1}\right)$ em função dos níveis de EM $\left(\mathrm{kcal} \mathrm{kg}^{-1}\right)$ e PB $(\%)$ no período de 1 a 21 dias de idade.

\begin{tabular}{llc}
\hline Equação de Regressão & $\mathrm{R}^{2}$ & Signif. \\
\hline $\mathrm{CR}=2440,42-27,3615 \times \mathrm{xB}-1,4488 \times \mathrm{xEM}+0,7431 \times \mathrm{PB}^{2}+0,0002841 \mathrm{xEM}^{2}$ & $90,8 \%$ & $* *$ \\
$\mathrm{PC}=136,117-0,10 \times \mathrm{xM}+9,41 \times \mathrm{PB}-0,4807 \mathrm{xB}^{2}+0,004465 \mathrm{xEMxPB}$ & $76,0 \%$ & $*$ \\
$\mathrm{GP}=45,5415-0,000937001 \times \mathrm{xMxPB}$ & $65,0 \%$ & $*$ \\
$\mathrm{CA}=4,22008-0,00000510878 \times \mathrm{xMxPB}$ & $60,0 \%$ & $*$ \\
\hline
\end{tabular}

Signif. = Significância; ** * Significativo a $1 \%$ e $5 \%$ de probabilidade, respectivamente; $\mathrm{R}^{2}=$ coeficiente de determinação.

Houve efeito linear $(\mathrm{P}<0,05)$ da interação EM e PB sobre o GP, pois se observou que $3100 \mathrm{kcal} \mathrm{EM} \mathrm{kg}^{-1}$ e $26 \%$ PB leva a um maior GP $(121,06 \mathrm{~g})$, o que corresponde ao consumo de $5,76 \mathrm{~g}$ de $\mathrm{PB} / \mathrm{dia} /$ codorna. CORRÊA et al. (2008), em trabalho com codornas de corte EV2, observaram efeito quadrático apenas da PB sobre o GP, sendo que a exigência de PB para um maior GP $(141,95 \mathrm{~g})$ é estimada em 30,65\%. Tais resultados indicam que uma variação no nível de EM utilizado pode alterar o GP das codornas.

RAJINI \& NARAHARI (1998) avaliaram o desempenho de codornas japonesas com rações contendo 24, 26 e 28\% PB e níveis de EM de 2400, 2600 e 2800 e verificaram melhor GP utilizando rações contendo 28\% PB, independentemente do nível de EM. Esses resultados indicam novos estudos em relação aos níveis de EM utilizado, pois o que se verificou neste caso é um efeito em conjunto da EM com a PB. Tal aspecto pode levar a uma redução nos custos da formulação das rações das codornas, visto que a PB é o ingrediente mais caro.

Houve efeito linear $(\mathrm{P}<0,05)$ da interação EM e PB sobre a CA, em que a utilização de 3100kcal EM $\mathrm{kg}^{-1}$ e 26\% de PB proporcionou uma melhor CA, sendo $3,80 \mathrm{~g} \mathrm{~g}^{-1}$. CORRÊA et al. (2007) observaram efeito linear $(\mathrm{P}<0,05)$ apenas $\mathrm{PB}$ sobre a $\mathrm{CA}$, sendo que os níveis de $28 \%$ PB e $3100 \mathrm{kcal} \mathrm{EM} \mathrm{kg}^{-1}$ proporcionaram um melhor CA $\left(1,67 \mathrm{~g} \mathrm{~g}^{-1}\right)$.

Os resultados da análise de regressão múltipla das variáveis, em função dos níveis de energia metabolizável (EM) e proteína bruta (PB) para o crescimento, encontram-se na tabela 3 . Houve efeito quadrático $(\mathrm{P}<0,05)$ da $\mathrm{EM}$ e $\mathrm{PB}$ sobre o $\mathrm{CR}$, pois com $2915 \mathrm{kcal}$ EM kg-1 com 26\% PB obtém-se um maior CR (105,75g). OLIVEIRA et al. (2002) observaram efeitos quadráticos do nível de EM sobre o CR, com mínimos estimados de consumo de ração para $3023 \mathrm{kcal} \mathrm{EM} \mathrm{kg}^{-1}$, em ração contendo $18 \%$ de PB. Esses resultados indicam que o nível de $\mathrm{PB}$ no presente trabalho está superior ao recomendado por OLIVEIRA et al. (2002), embora o nível energético da ração se aproxime da recomendação desses mesmos autores.

ANGULO et al. (1993) relataram que o CR de codornas japonesas, alimentadas com rações contendo $3000 \mathrm{kcal} \mathrm{EM} \mathrm{kg}^{-1}$, foi maior que o daquelas alimentadas com 3200kcal EM kg$~^{-1}$, no período de crescimento. Verifica-se, portanto, maior CR de codornas japonesas quando alimentadas com rações contendo menores níveis de EM.

Houve efeito linear $(\mathrm{P}<0,05)$ da EM e PB sobre o $\mathrm{PC}$, pois se observou que a ração com $3100 \mathrm{kcal}$ EM kg-1 e $26 \%$ PB proporciona maior PC $(223,08 \mathrm{~g})$.

Tabela 3 - Regressão múltipla do consumo de ração ( $\mathrm{CR} g$ ave ${ }^{-1}$ ), peso corporal (PC g ave ${ }^{-1}$ ), ganho de peso $\left(\mathrm{GP} g\right.$ ave $\left.\mathrm{e}^{-1}\right)$ e conversão alimentar $\left(\mathrm{CA} \mathrm{g} \mathrm{g}^{-1}\right)$ em função dos níveis de EM ( $\left.\mathrm{kcal} \mathrm{kg}^{-1}\right)$ e PB (\%) no período de 1 a 35 dias de idade.

\begin{tabular}{llc}
\hline Equação de Regressão & $\mathrm{R}^{2}$ & Signif. \\
\hline $\mathrm{CR}=4312,36-2,79899 \times \mathrm{xEM}+0,0004801 \mathrm{xEM}^{2}+0,115724 \mathrm{xPB}^{2}$ & $57,0 \%$ & $*$ \\
$\mathrm{PC}=186,648-3,39468 \mathrm{xB}+0,00154715 \times \mathrm{xMxPB}$ & $69,0 \%$ & $*$ \\
$\mathrm{GP}=339,211-21,82 \times \mathrm{PB}+0,473362 \times \mathrm{PB}^{2}+0,00671485 \mathrm{xEM}$ & $58,0 \%$ & $*$ \\
$\mathrm{CA}=3,48035-0,000717688 \times \mathrm{xEM}+0,0000211197 \mathrm{xEMxPB}$ & $45,0 \%$ & $*$ \\
\hline
\end{tabular}

Signif. $=$ Significância; $*$ Significativo a $5 \%$ de probabilidade $; R^{2}=$ coeficiente de determinação.

Ciência Rural, v.43, n.3, mar, 2013. 
Resultado semelhante foi encontrado por MARKS (1993), que verificou melhor PC em codornas de corte em crescimento, de ambos os sexos, com níveis de PB entre 24 e $27 \%$ com $3100 \mathrm{kcal} \mathrm{EM} \mathrm{kg}^{-1}$.

Houve efeito quadrático $(\mathrm{P}<0,05)$ da $\mathrm{PB}$ e linear da EM sobre o GP, 23\% PB com 3100kcal EM kg-1 leva a um maior GP $(112,69 \mathrm{~g})$. Com relação à $\mathrm{PB}$, resultado semelhante foi obtido por CORRÊA et al. (2007), que observaram bom desempenho para o GP das codornas com rações contendo $22 \%$ PB. Entretanto, esses mesmos autores recomendaram $2900 \mathrm{kcal} \mathrm{EM} \mathrm{kg}^{-1}$ para melhor GP no período de crescimento, sendo este nível inferior ao recomendado no presente trabalho. Houve efeito linear $(\mathrm{P}<0,05) \mathrm{da}$ EM e PB sobre o CA, em que se verificou melhor CA $\left(2,40 \mathrm{~g} \mathrm{~g}^{-1}\right)$ utilizando $3100 \mathrm{kcal} \mathrm{EM} \mathrm{kg}^{-1}$ e $18 \% \mathrm{~PB}$, o que indica que, nessa fase, níveis mais altos de EM e mais baixos de PB devem ser utilizados.

As equações de regressão múltipla das variáveis, em função dos níveis de energia metabolizável (EM) e proteína bruta $(\mathrm{PB})$ para o período de terminação, encontram-se na tabela 4. Houve efeito linear $(\mathrm{P}<0,05)$ da EM e PB sobre o CR, pois os níveis de 3100kcal EM $\mathrm{kg}^{-1}$ e $26 \% \mathrm{~PB}$, proporcionaram maior CR $(446,33 \mathrm{~g})$. MURAKAMI et al. (1993), avaliando níveis de 2800 e $3000 \mathrm{kcal} \mathrm{EM} \mathrm{kg}^{-1} \mathrm{em}^{2}$ rações com 20, 22, 24 e 26\% PB para codornas japonesas, verificaram efeito quadrático $(\mathrm{P}<0,05)$ da EM e $\mathrm{PB}$ sobre o $\mathrm{CR}$, pois os níveis proteicos e energéticos para o máximo CR foram de $20 \%$ de $\mathrm{PB}$ e $3000 \mathrm{kcal} \mathrm{EM} \mathrm{kg}^{-1}$. Esses resultados são inferiores aos do presente trabalho, uma vez que foram utilizadas codornas de corte, cujas exigências de crescimento são de fato superiores aos das codornas japonesas.

Houve efeito linear $(\mathrm{P}<0,05)$ da EM e PB sobre o PC, pois se verificou também que a utilização desses mesmos níveis nutricionais $\left(3100 \mathrm{kcal} \mathrm{EM} \mathrm{kg}^{-1} \mathrm{e}\right.$ $26 \% \mathrm{~PB})$ propiciou o maior PC $(279,46 \mathrm{~g})$. OLIVEIRA et al. (2002) verificaram efeito quadrático da PB sobre PC, em que a exigência protéica para maiores $\mathrm{PC}$ em codornas foi $24,73 \%$ PB. Já CORRÊA et al. (2007) observaram máximo PC na fase de terminação em codornas de corte, quando alimentadas com rações contendo $28 \%$ PB e $2900 \mathrm{kcal} \mathrm{EM} \mathrm{kg}^{-1}$, sendo níveis acima e abaixo, respectivamente, para PB e EM que os observados no presente estudo, sugerindo, portanto, a necessidade de mais estudos para determinação das exigências nutricionais em codornas de corte. Houve efeito linear e quadrático $(\mathrm{P}<0,05)$ da EM e PB sobre GP, no entanto, no estudo da equação de regressão, verificou-se a presença de sinais $(-\mathrm{e}+)$ nos efeitos quadráticos, o que indica a presença de um ponto de "sela" e, portanto, não se pode afirmar se o ponto (19\% $\mathrm{PB}$ e $2670 \mathrm{kcal} \mathrm{EM} \mathrm{kg}^{-1}$ ) determina um maior ou menor GP das codornas.

Houve efeito linear $(\mathrm{P}<0,05)$ da EM e PB sobre CA, já que a utilização de $2700 \mathrm{kcal} \mathrm{EM} \mathrm{kg}^{-1} \mathrm{e}$ $18 \% \mathrm{~PB}$ propiciou melhor $\mathrm{CA}\left(4,58 \mathrm{~g} \mathrm{~g}^{-1}\right)$. CORRÊA et al. (2007), trabalhando com codornas de corte em período de terminação, verificaram efeito quadrático da PB sobre CA, em que 23\% PB e 2900kcal EM kg-1 proporcionaram melhor $\mathrm{CA}\left(3,23 \mathrm{~g} \mathrm{~g}^{-1}\right)$. Tais resultados indicam que a utilização de níveis mais baixos de $\mathrm{PB}$ ou EM e sua ação em conjunto (interação) podem piorar a CA na fase de terminação, o que leva a perdas econômicas.

\section{CONCLUSÃO}

Para codornas europeias na fase inicial, recomenda-se $26 \%$ de PB e 3100kcal EM kg-1. Para a fase de crescimento, sugere-se $3100 \mathrm{kcal} \mathrm{EM} \mathrm{kg}^{-1}$ e $23 \%$ de PB, já, para a fase de terminação, recomenda-se $26 \%$

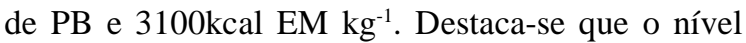
máximo de proteína avaliado no presente estudo foi de $26 \%$ PB, sendo que, possivelmente, melhores resultados poderão ser encontrados com níveis mais elevados de PB, acima dos estudados neste trabalho, em função da elevada taxa de crescimento das codornas de corte, principalmente nas primeiras semanas de vida.

Tabela 4 - Regressão múltipla do consumo de ração (CR g ave ${ }^{-1}$ ), peso corporal (PC g ave ${ }^{-1}$ ), ganho de peso $\left(\mathrm{GP} g\right.$ ave $\left.\mathrm{e}^{-1}\right)$ e conversão alimentar $\left(\mathrm{CA} \mathrm{g} \mathrm{g}^{-1}\right)$ em função dos níveis de $\mathrm{EM}\left(\mathrm{kcal} \mathrm{kg}^{-1}\right)$ e PB $(\%)$ no período de $1 \mathrm{a} 49$ dias de idade.

\begin{tabular}{lcc}
\hline Equação de Regressão & $\mathrm{R}^{2}$ & Signif. \\
\hline $\mathrm{CR}=-261,11+0,216398 \times \mathrm{xM}+18,4804 \times \mathrm{xB}-0,005507 \times \mathrm{xMxPB}$ & $72,0 \%$ & $*$ \\
$\mathrm{PC}=214,905+0,000801 \times \mathrm{xEMPB}$ & $46,0 \%$ & $*$ \\
$\mathrm{GP}=481,442-0,204413 \times \mathrm{xEM}-0,000038 \mathrm{xEM}^{2}-14,4107 \times \mathrm{xB}+0,386115 \times \mathrm{xB}^{2}$ & $56,0 \%$ & $*$ \\
$\mathrm{CA}=3,123+0,00003 \times \mathrm{xMxPB}$ & $45,0 \%$ & $*$ \\
\hline
\end{tabular}

Signif. = Significância; $*$ Significativo a $5 \%$ de probabilidade; $\mathrm{R}^{2}=$ coeficiente de determinação. 


\section{AGRADECIMENTO}

Os autores agradecem ao apoio financeiro recebido da Coordenação de Aperfeiçoamento de Pessoal de Nível Superior (CAPES), Conselho Nacional de Desenvolvimento Científico e Tecnológico (CNPq) e Fundação de Amparo à Pesquisa do estado de Minas Gerais (FAPEMIG).

\section{COMITÊ DE ÉTICA E BIOSSEGURANÇA}

Esta pesquisa foi aprovada pela Comissão de Ética em Pesquisa com Animais (Processo 007-2010), vinculado à Universidade Federal dos vales do Jequitinhonha e Mucuri.

\section{REFERÊNCIAS}

ANGULO, E. et al. Effect of diet density and pelleting on productive parameters of Japanese quail. Poultry Science, v.72, n.3, p.607-610, 1993. Disponível em: <http:// www.ncbi.nlm.nih.gov/pubmed/8464802>. Acesso em: 18 out. 2009. doi: $10.1590 / 8464802$.

CORRÊA, G.S.S. et al. Nível de proteína bruta para codornas de corte durante o período de crescimento. Arquivo Brasileiro de Medicina Veterinária e Zootecnia, v.60, n.1, p.209217, 2008. Disponível em: <http://dx.doi.org/10.1590/S010209352008000100029>. Acesso em: 10 jun. 2009. doi: 10.1590/ S0102-09352008000100029.

CORRÊA, G.S.S. et al. Exigências de proteína bruta e energia metabolizável em codornas de corte durante a fase de crescimento. Arquivo Brasileiro de Medicina Veterinária e Zootecnia, v.59, n.2, p.488-494, 2007. Disponível em: <http://dx.doi.org/ 10.1590/S0102-09352007000200032>. Acesso em: 8 jul. 2009. doi: 10.1590/S0102-09352007000200032.

FREITAS, A.C. et al. Níveis de proteína bruta e energia metabolizável na ração para codornas de corte. Revista Brasileira de Zootecnia, v.35, n.4, p.1705-1710, 2006. Disponível em: <http://dx.doi.org/ 10.1590/S1516-35982006000600018>. Acesso em: 5 maio, 2009. doi: $10.1590 / \mathrm{S} 1516-35982006000600018$.

LISBOA, J.S. et al. Rendimento de carcaça de três grupos genéticos de frangos de corte alimentados com rações contendo diferentes teores de proteína. Revista Brasileira de Zootecnia, v.28, n.3, p.548-554, 1999. Disponível em: <http://www.sbz.org.br/ revista/artigos/2004.pdf>. Acesso em: 10 jun. 2009.

NRC (NATIONAL RESEARCH COUNCIL). Nutrient requirements of poultry. Washington, D.C.: National Academic, 1994. 145p.
MARKS, H.L. The influence of dietary protein levels on body weight of Japanese quail lines selected under high and low protein diets. Poultry Science, v.72, n.6, p.1012-1017, 1993. Disponível em: 〈http://ps.fass.org/content/72/6/1012〉. Acesso em: 8 maio, 2009. doi: 10.3382/ps.0721012.

MÓRI, C. et al. Desempenho e rendimento de carcaça de quatro grupos genéticos de codornas para produção de carne. Revista Brasileira de Zootecnia, v.34, n.3, p.870-875, 2005. Disponível em: 〈http://www.scielo.br/pdf/rbz/v34n3/a19v34n3.pdf〉. Acesso em: 7 ago. 2009.

MURAKAMI, A.E. et al. Níveis de proteína e energia em rações para codornas Japonesas (Coturnix coturnix japonica) em crescimento. Revista da Sociedade Brasileira de Zootecnia, v.22, n.4, p.534-540, 1993. Disponível em: <http:/ /www.scielo.br/scielo.php?script=sci_nlinks\&ref $=000119 \&$ pid $=S 01020935200200020001100006 \& \operatorname{lng}=e n>$. Acesso em: 6 maio, 2009. doi: S01020935200200020001100006.

OLIVEIRA, N.T.E. et al. Exigências de proteína bruta e energia metabolizável para codornas japonesas machos criadas para a produção de carne. Arquivo Brasileiro de Medicina Veterinária e Zootecnia, v.54, n.2, p.196-203, 2002. Disponível em: <http://dx.doi.org/10.1590/S010209352002000200011>. Acesso em: 4 de jun. 2009. doi: 10.1590/S0102-09352002000200011.

RAJINI, R.A.; NARAHARI, D. Dietary energy and protein requirements of growing japanese quails in the tropics. Indian Journal of Animal Science, v.68, n.10, p.1082-1086, 1998. Disponível em: <http://www.scielo.br/scielo.php?script= sci_nlinks\&ref $=000112 \&$ pid $=$ S01020935200700050002700018 \&lng=en>. Acesso em: 3 fev. 2009. doi: S0102/ 0935200700050002700018 .

ROStagnO, H.S. et al. Composição de alimentos e exigências nutricionais (Tabelas Brasileiras). Viçosa: Universidade Federal de Viçosa, 2000. 141p.

SILVA, E.L. et al. Redução dos níveis de proteína e suplementação aminoacídica em rações para codornas européias (Coturnix coturnix coturnix). Revista Brasileira de Zootecnia, v.35, n.3, p.822-829, 2006. Disponível em: <http://www.scielo.br/ pdf/rbz/v35n3/30076>. Acesso em: 10 de jun. 2009.

SAEG. Sistema para análise estatística e genética - Versão 8.0. Viçosa, MG: Fundação Arthur Bernardes, 2007. 59p. (Manual do usuário). 